\title{
Interdisciplinaridade e educação ambiental crítica: questões epistemológicas a partir do materialismo histórico-dialético
}

\section{Interdisciplinarity and critical environmental education: epistemological issues from historical-dialectical materialism}

\author{
César Augusto Soares da Costa ${ }^{1}$. Carlos Frederico Bernardo Loureiro ${ }^{2}$
}

\begin{abstract}
Resumo: O ensaio discute a relação entre interdisciplinaridade e Educação Ambiental (EA) crítica à luz das questões epistêmicas sob o foco do materialismo histórico-dialético, o qual está organizado em três momentos: na introdução, indicamos o cenário da discussão ambiental em face do debate contemporâneo, e suas formulações teóricas que propõem dimensionar a EA a partir do conhecimento crítico, histórico e complexo. No segundo, situamos, à luz do materialismo histórico-dialético, as bases conceituais e metodológicas da educação ambiental e seus vínculos com a interdisciplinaridade. No terceiro e último, apontamos quais implicações epistemológicas o método materialista histórico-dialético pode conferir à interdisciplinaridade e à EA crítica. É preciso considerar os componentes ontológicos e históricos de intervenção humana no ambiente, cabendo aos processos de EA crítica refletirem sobre a dinâmica da relação sociedade-natureza, os quais, sem esta dimensão, tornam o debate ambiental simplificado, fragmentado e despolitizado pela negação da materialidade contida nas relações sociais.
\end{abstract}

Palavras-chave: Educação Ambiental crítica. Interdisciplinaridade. Materialismo histórico-dialético.

Abstract: The essay discusses the relationship between interdisciplinarity and environmental education (EE) criticism in the light of epistemic issues from the perspective of historical and dialectical materialism, which is organized in three stages: in the introduction, we recommend the setting of environmental discussion in the face of the contemporary debate, and its theoretical formulations proposed to scale the EE from the critical, historical and complex knowledge. In the second, we situate in the light of historical and dialectical materialism conceptual and methodological bases of environmental education and its links with interdisciplinarity. In the third and last, we point out which epistemological implications of the historical and dialectical materialist method can give the interdisciplinary and critical EE. One must consider the historical and ontological components of human intervention in the environment, leaving the critical environmental processes to reflect on the dynamics of the relationship between society and nature, which without this dimension, make simplified environmental debate, fragmented and depoliticized by the negation of materiality contained in social relations.

Keywords: Critical environmental education. Interdisciplinarity. Historical-dialectical materialism.

\footnotetext{
${ }^{1}$ Programa de Pós-Graduação em Educação Ambiental, Universidade Federal do Rio Grande (FURG), Campus Carreiros, Avenida Itália km. 8, Carreiros, CEP 96201-900, Rio Grande, RS, Brasil. E-mail: <csc193@hotmail.com>

${ }^{2}$ Faculdade de Educação, Universidade Federal do Rio de Janeiro (UFRJ), Rio de Janeiro, RJ, Brasil.
} 


\section{Introdução}

Do ponto de vista político-epistemológico, a emergência e o entendimento da questão ambiental como problema interdisciplinar, a ser enfrentado a partir de um conhecimento crítico, histórico e complexo, são respostas não somente à crise da racionalidade da modernidade, mas, também, à produção social da ciência e à materialidade desta no capitalismo globalizado (FRIGOTTTO, 2004). Desde o mercantilismo europeu e, mais acentuadamente, com a Revolução Industrial, a atividade interventora e transformadora dos seres humanos em sua relação metabólica com a natureza vem se tornando cada vez mais destrutiva e universal, sob um modo de produção que impõe a expropriação do trabalho e o uso intensivo de recursos naturais (TOZONI-REIS, 2004). E a forma como se produz ciência desde o paradigma cartesiano e do positivismo está relacionada à expansão desse padrão societário, legitimando e reproduzindo a fragmentação da compreensão do real, a divisão social do trabalho e a cisão sociedade-natureza (LOUREIRO, 2012).

Neste cenário, a educação ambiental em particular, e o ambientalismo em geral, argumentam, desde a década de 1960, que a crise contemporânea é uma crise civilizatória, dos referenciais epistemológicos, filosóficos e políticos que vêm sustentando a modernidade capitalista e eurocêntrica (QUINTAS, 2009).

$\mathrm{Na}$ educação ambiental, a defesa da interdisciplinaridade se observa em vários de suas Leis e documentos normativos. Por exemplo, a Política Nacional de Educação Ambiental (PNEA), Lei n. 9795/99 (BRASIL, 1999), afirma, em seu artigo $4^{\circ}$, que são princípios desta a perspectiva multi, inter e transdisciplinar. Encontramos similaridade nos Parâmetros Curriculares Nacionais, que afirmam, como uma temática transversal e interdisciplinar, a questão ambiental (BRASIL, 1997). Nas Diretrizes Curriculares Nacionais de Educação Ambiental, publicadas em 2012 (BRASIL, 2012), novamente observamos a defesa da educação ambiental como uma dimensão integrada da educação, e a adoção de uma perspectiva interdisciplinar, que promova o conhecimento do ambiente enquanto totalidade (conceito esse que também aparece na PNEA).

Em relação às discussões no campo ambiental, muitas alternativas têm sido propostas. As tendências presentes nestes debates referem-se, em síntese, à totalidade, à complexidade e ao sistemismo. A ideia é de superação da fragmentação presente na prática histórica de construção do conhecimento, enquanto exigência para a criação de conhecimentos que permitam uma nova visão de natureza, mundo e inserção humana no planeta (MORIN, 2003; PRIGOGINE; STENGERS, 1997).

Este trabalho, de caráter ensaístico, visa contribuir para os debates acerca da interdisciplinaridade na educação ambiental, no que se refere às suas implicações epistemológicas à luz do método materialista histórico-dialético, considerando, para tanto, sua importância na construção do campo crítico da educação ambiental brasileira (LOUREIRO, 2004, 2012; LOUREIRO et al., 2009), com larga influência nas políticas públicas, movimentos sociais e na produção teórica e metodológica vinculadas aos diferentes espaços pedagógicos. 


\section{Interdisciplinaridade e materialismo histórico-dialético}

Concebemos que o vínculo entre a educação ambiental, a dialética marxista e a interdisciplinaridade, em sua fundamentação crítica, se mantém enquanto materialidade que contribua para a transformação da práxis, ao assumir a criticidade das suas proposições. Uma crítica que se relaciona à radicalidade das lutas sociais perante a expropriação material e relações sociais desiguais opressoras, visando à transformação da realidade.

Assim posto, negar a dimensão política da educação e o modo de produção social da ciência, é negar a complexidade do real e afirmar um paradigma instaurado em nossas compreensões de educação ambiental que dissolveu a relação sociedade-natureza num só aspecto, o natural (LOUREIRO, 2005), sem contemplar as mediações sociais. Negar o caráter de classe presente na ciência, em seus usos e discursos, e no modo como produzimos conhecimento, significa, portanto, continuar propondo uma educação ambiental interdisciplinar que dicotomiza sociedade-natureza, que naturaliza o que é histórico, e que se apresenta como apolítica. À luz do que foi dito, este elemento implica reconhecer a EA como um "ato político" (FREIRE, 1993), visto que ela é construída por meio das relações sociais e pedagógicas, onde a consciência política e a capacidade crítica são necessárias para agirmos no ambiente.

Para reforçar nossa linha de argumentação, devemos destacar que a recusa à fragmentação do conhecimento científico, como exigência para novas relações com a natureza, surge no contexto de expansão de um capitalismo que passa a se reproduzir com forte ênfase nos processos especulativos financeiros e na utilização das ciências, do conhecimento, da tecnologia e da informação como forças produtivas, materializadas, preponderantemente, pelo complexo empresarial-militar. Assim, o sociometabolismo do capital potencializa e diversifica processos de acumulação e dominação, ao vincular, à necessidade de especialidade técnica decorrente da divisão do trabalho, os conhecimentos multidimensionais e o uso da informação em tempo real (MÉSZÁROS, 2006). Vivemos, portanto, em um momento regido não mais exclusivamente por um princípio mecânico-industrial de organização da produção, mas, também, por um princípio cibernético, flexível, com profundos efeitos na subjetividade humana (PRADO, 2005), onde a crítica à fragmentação do conhecimento na defesa da interdisciplinaridade passa, necessariamente, pela crítica ao modo como este é produzido, por quem é produzido e para que fins. Isso implica, em última instância, a não-dissociação entreo debate epistêmico do político e econômico.

Neste âmbito percebemos que a interdisciplinaridade na produção do conhecimento é imperativa, mas é também uma questão que está lotada na materialidade das relações capitalistas de produção da existência. Sem entrarmos na aridez desta materialidade, o problema da interdisciplinaridade permanece num espaço lógico-formal, de um discurso de intencionalidade que pouco se objetiva na educação. Em relação à importância do conhecimento vinculado à prática, asseguramos que a prática produtiva humana está antropologicamente equacionada por expressar a coletividade, pois a espécie é ímpar na medida em que se efetiva em sociedade. Não se é humano fora de um tecido social. Logo, o conhecimento não se estabelece a partir de nexos lógico-formais; ele se apresenta de maneira axiológica nos problemas de natureza ético-política (SEVERINO, 2004).

Historicamente, a interdisciplinaridade surgiu no continente europeu, sobretudo na França e Itália, em meio à década de 1960, quando os movimentos estudantis tinham, como 
sua principal reivindicação, um novo estatuto de universidade. Tal questão apontava a alienação da universidade dos problemas cotidianos, que incitava o olhar dos seus alunos numa única e restrita visão de mundo. É “"neste contexto das críticas ao atual modelo e padrão de conhecimento construído com a legitimação da ciência moderna, hegemônico no processo educativo institucionalizado, que a temática da interdisciplinaridade ganha notoriedade" (SILVA, 2009, p. 4).

$\mathrm{O}$ termo interdisciplinaridade caracteriza-se pelo enfoque científico e pedagógico que se estabelece por um diálogo entre especialistas de diversas áreas sobre uma determinada temática, redefinindo os limites dos objetos de pesquisa específicos, seus conceitos e metodologias associadas, ampliando o conhecimento do real em sua dinâmica (ASSMANN, 1999). Isto aponta que a interdisciplinaridade pode ser compreendida como esse processo aberto, pessoal e coletivo, de construção do conhecimento pelo diálogo e aproximação entre ciências e saberes, que permita a apreensão da totalidade social, sem, contudo, idealizar o todo ou "misturar" teorias e metodologias que não são compatíveis do ponto de vista ontológico (da constituição do ser social). Instituir a interdisciplinaridade não é o mesmo que defender um pluralismo sem criticidade, em que o complexo se dilui na simples convivência do diverso. Compreender o complexo exige método, e método exige coerência epistemológica e intencionalidade explicitada.

Consequentemente, as dificuldades surgem no modo de fundamentar uma base filosófica acerca da interdisciplinaridade na educação ambiental crítica que dê conta de, ao negar a fragmentação e o isolamento entre ciências e disciplinas, contribuir para a superação de uma realidade vista como destrutiva e alienante. Ou seja, o desafio está em como configurar uma perspectiva interdisciplinar mais próxima de interesses concretos, urgindo ao ponto de se colocar a serviço do conhecimento e do enfrentamento dos problemas suscitados na realidade desigual do capitalismo. Desse modo, ao se pensar a interdisciplinaridade crítica se faz condição primordial torná-la aberta ao encontro de suas possibilidades reais, pelo confronto teoria-prática, reflexão-ação, em contextos sociais determinados (FOLLARI, 2004).

O contraponto de que partimos, para tanto, é o aporte interdisciplinar originário do paradigma marxista dialético, que, historicamente, surge como proposta crítica ao movimento existente. Assim, percebemos a necessidade da abordagem epistemológica da interdisciplinaridade de forma histórica e crítica, que não exclua a necessidade e a possibilidade de avançarmos na produção do conhecimento científico, enquanto dimensão constitutiva da emancipação humana. Isso não implica que interdisciplinaridade e especialidade (disciplina) não possam conviver em diálogo, dado que o "genérico e o específico não são excludentes" (BIANCHETTI; JANTSCH, 2004). Pelo contrário, entendemos que a interdisciplinaridade exige o conteúdo disciplinar para a compreensão das mútuas determinações entre universal e particular na constituição do que é singular. Isso permite localizar o problema da disciplina como sinônimo de fragmentação: no modo como o currículo é concebido e gerido nas instituições educacionais, nas relações hierarquizadas entre ciências e conhecimentos escolares, e na função social da educação em uma sociedade de classes.

Entendemos que o trabalho interdisciplinar, do ponto de vista crítico, se verifica na produção e na socialização do conhecimento no campo das ciências e no campo educativo, decorrendo da forma de o ser genérico humano produzir-se enquanto ser social e enquanto sujeito do conhecimento. Daí, a necessidade de se buscar compreender que a interdisciplinaridade na produção do conhecimento é fundada no caráter dialético da realidade social e na natureza intersubjetiva de sua apreensão (LUKÁCS, 2010). 
Desse modo, a compreensão da categoria da totalidade concreta é necessária para assinalarmos a interdisciplinaridade como necessidade imperativa na construção do conhecimento social. Como adverte Kosik (1978), a totalidade não é tudo e nem a busca do princípio fundador de tudo. Analisar dentro da concepção de totalidade concreta significa buscar explicar, a partir de um objeto de pesquisa delimitado, as múltiplas determinações e mediações históricas que o constituem. Esta remete a um conjunto estruturado de relações mutuamente determinadas e mediadas, que formam uma unidade que permite compreender algo. Como a realidade é movimento na/da história, reconstruída pela ação prática e transformadora dos seres humanos, a totalidade também transborda para a forma de apreender esta realidade, ou seja, transborda para a subjetividade e para um método que busca tal apreensão na práxis. Segundo Kosik (1978, p. 34):

A compreensão dialética da totalidade significa não só que as partes se encontram em relação de interna interação e conexão entre si e com o todo, mas também que o todo não pode ser petrificado na abstração situada por cima das partes, visto que o todo se cria a si mesmo nas interações das partes.

Mas vejamos como Marx faz o enfrentamento da questão epistemológica presente no seu método à luz da interdisciplinaridade:

Quando estudamos um dado país do ponto de vista da Economia Política, começamos por sua população, sua divisão em classes, sua repartição entre cidades e campo, na orla marítima; os diferentes ramos da produção, a exportação e a importação, a produção e o consumo anuais, os preços das mercadorias etc. Parece que o correto é começar pelo real e pelo concreto, que são a pressuposição prévia e efetiva; assim, em Economia, por exemplo, começar-se-ia pela população, que é a base e o sujeito do ato social de produção como um todo. (MARX, 1982, p. 14)

Destacamos alguns elementos relevantes desta citação sobre a qual Marx (1982) introduz o método crítico da economia política. Em primeiro lugar, a referência da análise marxiana pela população, enquanto o "real concreto" dirige-se à prática tradicional da economia política burguesa clássica, tendo o objetivo de apontá-la como equivocada. Pois este todo que se tem como primeira visão da realidade, na medida em que é uma apreensão sincrética, imediata, não pode ser considerado concreto. $\mathrm{O}$ todo que se tem nesse primeiro momento é somente um abstrato, ausente das mediações e determinações conceituais capazes de torná-lo cognoscível. Como assinala: "a população é abstração, se desprezamos, por exemplo, as classes que a compõem” (MARX, 1982, p. 14). Para o método, esse todo apreendido ainda é indiferenciado quanto a seus momentos constitutivos, uma vez que permanece no nível do concreto empírico. Num primeiro movimento analítico, descobrimos a população dividida em classes, sendo que estas últimas se tornam incompreensíveis sem investigarmos os elementos capital e trabalho. Segundo Marx, é possível concluirmos que o denominado todo de onde parte a Economia Política, embora apareça imediato como real e concreto, é um abstrato desordenado (OLIVEIRA, 2002), como o próprio Marx (1982, p. 14) assevera: "se começássemos pela população, teríamos uma representação caótica do todo". 
Assim, não podemos concluir pela simples desconsideração daquela representação que aparece caótica. Logo, identificado o concreto imediato apenas como ponto de partida da representação, impõe-se um passo analítico que seja capaz de determinar com maior precisão seus elementos constitutivos. Ou seja,

[...] se começássemos pela população, teríamos uma representação caótica do todo, e através de uma determinação mais precisa, através de uma análise, chegaríamos a conceitos cada vez mais simples; do concreto idealizado passaríamos a abstrações cada vez mais tênues até atingirmos determinações as mais simples. (MARX, 1982, p. 14)

Marx (1982 apud OLIVEIRA, 2002) relaciona as determinações sociais às categorias mais abstratas, uma vez que este filão metodológico revela o equívoco da clássica economia burguesa, que permanecia ligada à aparência dos fatos, amarrados a uma falsa concepção da noção de concreto. A análise, na medida em que implica particularizações e o isolamento dos elementos mais sutis, exige categorizações por conceitos abstratos, o que indica a impossibilidade do estabelecimento dos vínculos que permitiriam recompor a complexa estrutura social. Numa passagem célebre, Marx (1982) assinala, de maneira mais incisiva, seu método que se opõe aos economistas clássicos:

Os economistas do século XVII, por exemplo, começam sempre pelo todo vivo: a população, a nação, o Estado, vários Estados etc.; mas terminam sempre por descobrir, por meio da análise, certo número de relações gerais abstratas que são determinantes, tais como a divisão do trabalho, o dinheiro, o valor etc. Esses elementos isolados, uma vez mais ou menos fixados e abstraídos, dão origem aos sistemas econômicos, que se elevam do simples, tal como trabalho, divisão do trabalho, necessidade, valor de troca, até o Estado, a troca entre as nações e o mercado mundial. O último método é manifestamente o método cientificamente exato. O concreto é concreto porque é a síntese de muitas determinações, isto é, unidade do diverso. Por isso o concreto aparece no pensamento como o processo da síntese, como resultado, não como ponto de partida, ainda que seja o ponto de partida efetivo e, portanto, o ponto de partida também, da intuição e da representação. No primeiro método, a representação plena volatiliza-se em determinações abstratas, no segundo, as determinações abstratas conduzem à reprodução do concreto por meio do pensamento. (MARX, 1982, p. 14)

Consequentemente, as correlações apontadas pelo método marxista assinalam que a articulação das categorias abstratas sob seu princípio ordenador e a compreensão mais decomposta do concreto constituem partes de um mesmo problema. A "viagem de modo inverso" visa tornar as categorias abstratas resultantes do passo analítico, e inter-relacioná-las como momentos de um único processo por meio do pensamento, uma totalidade diferenciada e determinada, ou seja, um concreto. 
Assim, o caminho da síntese, pelo fato de articular categorias abstratas numa rede de reflexão, confere-lhes um sentido determinado dentro da ordem da totalidade. Assim, o todo imediato, o concreto empírico imediatamente apreendido é superado no concreto sintético. (OLIVEIRA, 2002, p. 73)

Concebemos que $O$ Capital de Marx seja tomado como exemplo de uma obra interdisciplinar, por primar, em sua abordagem, pela unificação de variadas ciências, com vistas ao estudo multilateral de determinada formação social. Efetiva-se, nesse estudo, uma unificação entre a economia política e a sociologia, a historiografia, a demografia, a geografia econômica e a antropologia (GORENDER, 1996), com introdução de aspectos relevantes da química, agronomia e da biologia no que diz respeito aos estudos fundiários e ao metabolismo sociedade-natureza (FOSTER, 2005). Assim, se o concreto é unidade do diverso, síntese de múltiplas determinações (MARX, 1982), a interdisciplinaridade na educação ambiental não pode ser sustentada pela simples primazia do projeto em parceria, omitindo a dimensão política dos sujeitos envolvidos no processo de compreensão do conhecimento e das relações lotadas de materialidade, conflitos e contradições inerentes à dimensão práxica dos sujeitos.

É por meio de Marx e sua exposição, onde nela se realiza sua crítica, que buscamos sustentação teórico-metodológica de interpretação e explicação da realidade ambiental. Compreendemos que tal método possui relevante contribuição ao debate ambiental pelo sentido único que postula a relação sociedade-natureza (aspecto ontológico do ser social e histórico), bem como do entendimento crítico e reflexivo da questão ambiental, posto que permite estabelecer concretamente as determinações sociais dos problemas e conflitos ambientais. Situamos que a dialética marxista é um instrumento de entendimento e ação na realidade, se constituindo numa visão de humanidade, sociedade, natureza e mundo que não separa sociedade-natureza. Muito pelo contrário, é nesta que se afirma a realidade complexa e dinâmica, em que os entes se constituem em relações das quais emergem a unidade e a particularidade (LOUREIRO, 2006b).

Da mesma maneira, cabe assinalar que é na prática que se opera a síntese entre teoria e realidade (SEVERINO, 2004). Tomando a ciência como um aspecto limitado da realidade, a dialética possui por objetivo a compreensão do mundo em seu conjunto, considerando as coisas e os fenômenos numa unidade de contrários, num encadeamento de relações, de modificações e de movimento contínuo. Entretanto, a dialética não tem a pretensão de se separar da ciência, pois é por meio da mesma que ela pode atingir seu desenvolvimento, assim como a superação do modo como esta se institui.

Assim, a discussão ambiental analisada em sua dimensão epistêmica e pedagógica, exige reflexões acerca da sua problemática. Segundo Gorender (1996), também em O Capital, a questão ambiental se apresenta de modo crítico no escopo marxista, onde alude que:

A humanização da natureza nem sempre tem sido um processo harmônico. Marx foi dos primeiros a apontarem o caráter predador da burguesia, com reiteradas referências, por exemplo, à destruição dos recursos naturais pela agricultura capitalista. Sob este aspecto, merece ser considerado precursor dos modernos movimentos de defesa da ecologia em benefício da vida humana. Do ponto de vista da Antropologia, o que 
sobreleva é a relação do homem com a natureza por meio do trabalho e a humanização sob o aspecto de autocriação do homem no processo de transformação da natureza pelo trabalho. As mudanças nas formas de trabalho constituem os indicadores básicos da mudança das relações de produção e das formas sociais em geral do intercurso humano. $\mathrm{O}$ trabalho é, portanto, o fundamento antropológico das relações econômicas e sociais em geral. (GORENDER, 1996, p. 22)

A partir desta premissa, concebemos que o método dialético terá de dar lugar ao heterogêneo de suas contradições, apresentando-se ao ato de fazer-se inacabado (visto como processos abertos e continuados) e incapaz de fechamento e de totalizações (no sentido de um todo fechado e acabado), mas num viés teórico marcado às diferenças, aos acontecimentos e à subjetividade que não se encerre aos limites de uma razão abstrata e generalizante (FOLLARI, 2004). Nesta lógica, a concepção dialética marxista não separa, em nenhum momento, teoria (conhecimento) da prática (ação), do qual a teoria não deve ser tomada como um dogma irrefutável, mas deve orientar, servir de modelo para a ação (SCHMIED-KOWARZIK, 1983). Em consequência, a prática será o critério de verdade da teoria, já que o conhecimento surge a partir da prática e a ela se volta dialeticamente. Exemplo clássico vem expresso por Marx (1987) em sua II Tese sobre Feuerbach, onde assevera que a questão de saber, se cabe ao pensamento humano uma verdade objetiva, não é uma questão teórica, mas prática. É na práxis que o homem deve demonstrar a verdade, isto é, a realidade, o caráter terreno de seu pensamento (MARX; ENGELS, 1977). Sua concepção de práxis é válida na medida em que a teoria como guia de ação orienta a atividade humana, eminentemente revolucionária, e teórica, uma vez que se presta a uma relação consciente de sua atividade (VÁSQUEZ, 2008). Na esteira do pensamento marxiano, Gramsci concebe a dialética marxista como filosofia da práxis, sendo um novo modo de pensar o mundo e realidade e de conceber a constituição do ser social - e, em seu bojo, das instituições sociais que materializam a exteriorização humana em seu fazer-se.

Significado que desponta no contexto latino-americano marcado por contextos opressores como uma arma de luta, porque ela não simplesmente polemiza, mas serve à elaboração do pensamento crítico da realidade para transformá-la. Nesse caso, a transformação das coisas só é possível porque, no seu interior, por serem complexos relacionais, coexistem forças opostas que tendem à unidade e à oposição, à lógica dos contrários, à contradição, lei fundamental da dialética.

\section{Interdisciplinaridade, método dialético e educação ambiental crítica}

Na concepção de Dias (2003, p. 98), na perspectiva da Conferência Intergovernamental da Educação Ambiental de Tbilisi (1977), a educação ambiental passou a ter a seguinte definição: “dimensão dada ao conteúdo e à prática da educação, orientada para a resolução dos problemas concretos do meio ambiente através de enfoques interdisciplinares e de uma participação ativa e responsável de cada indivíduo e da coletividade." A Conferência Intergovernamental sobre educação ambiental de Tbilisi propôs como um dos princípios básicos da educação ambiental: aplicar um enfoque interdisciplinar, aproveitando o conteúdo específico de cada disciplina, de modo que se adquira uma perspectiva global e equilibrada. Segundo Dias (2003 p. 117), "pela 
própria natureza do ambiente, dadas as suas múltiplas interações de fundo ecológico, político, social, econômico, ético, cultural, científico e tecnológico, não se poderia tratar o assunto em uma única disciplina."

Para tentar colocar em prática as recomendações da Conferência de Tbilisi, como foi dito na introdução, o Brasil aprovou e sancionou a Lei 9.795/99 - Política Nacional de Educação Ambiental (BRASIL, 1999), estabelecendo a educação ambiental como um componente essencial e permanente da educação nacional, devendo estar presente, de forma articulada, em todos os níveis e modalidades do processo educativo, em caráter formal e não formal.

A educação ambiental crítica, diante do que foi exposto em termos de método e de marco para o campo, se coaduna com a dialética marxista, pois entendemos que todo e parte, dialeticamente, são um movimento dinâmico, contraditório e complementar, mutuamente constituídos (LOUREIRO, 2004). Ao contrário, recairemos num holismo generalista, no globalismo desconexo da localidade (estruturalismo: quando o todo domina as partes), ou na fragmentação e isolamento das partes (funcionalismo: quando a parte domina o todo ou ignora o todo) para entendermos nossa relação com o ambiente. Ou, em termos pedagógicos, considerar que a ação dos indivíduos para os indivíduos seja, por si só, suficiente por meio de práticas particularizadas, sem pensar no movimento de transformação da sociedade para o indivíduo (LOUREIRO, 2006a).

Dentro desta discussão, seria inevitável não recorrermos a duas contribuições relevantes, embebidas da dialética marxista, relativas à problemática social e epistemológica em linguagens e concepções aproximadas na Pedagogia do Oprimido de Paulo Freire (1993) e na Filosofia da libertação de Enrique Dussel (1986). Ambos pensadores são identificados com a dialética marxista, mas não necessariamente com o conjunto do marxismo. Entendemos que ambos ilustram a discussão teórica feita e trazem respeitáveis contribuições para que entendamos a questão do fazer interdisciplinar em uma proposta crítica de educação ambiental. É evidente que a filosofia de Dussel não pode ser tratada como uma filosofia educacional, muito menos ambiental, haja vista que, em seus escritos, não prevalece uma intenção pedagógica (embora seja um conceito no escopo de seu pensamento), como, também, não podemos assinalar que a obra de Paulo Freire tenha uma preocupação ambiental. Apontamos que ambos os pensadores tematizaram um pensamento filosófico-político que, na história da América Latina e na história da educação, teve expressiva influência nas pedagogias críticas e nos instrumentaliza para refletirmos criticamente a sociedade, bem como o contraponto à efetivação dos projetos societários vigentes que excluem o ser humano da possibilidade de vir-a-ser mais (ZITKOSKI, 2007).

Em Dussel (1986), constatamos a preocupação fundamental com a Libertação dos sujeitos envolvidos no processo de opressão do sistema colonial europeu, deixando chagas sociais em nosso continente. Desse modo, o autor nos propõe refletir sobre a nossa condição de sujeitos inseridos na realidade social, para que possamos desenvolver uma perspectiva crítica dos acontecimentos sociais, políticos, culturais e econômicos em torno do sistema vigente. A abordagem latino-americana de Dussel encontra sua vitalidade e alcance crítico neste esforço de diálogo e aproximação com a proposta de Paulo Freire. Assim, nesta perspectiva, somos capazes de descobrir um aspecto fundamental: a existência de muitos mundos diferentes dentro do nosso mundo: a "outridade latino-americana" (DUSSEL, 1986), dentro da nossa realidade. Metodologicamente, optamos por valorizar o foco de análise na educação, trazendo o enfoque da filosofia e da educação libertadora, por reconhecermos a importância que ela ocupa, enquanto práxis, orientação e efetividade histórica, em nosso continente (COSTA, 2011). 
A Filosofia da Libertação de Enrique Dussel (1986) possui um propósito único: libertar filosófico-politicamente. Ou seja, quer libertar-nos politicamente, mostrando-nos alguns mecanismos de dominação e exploração que, normalmente, nos passam despercebidos ao cotidiano. A libertação filosófica e a libertação política se completam e são inseparáveis no método dusseliano, pois contemplam todas as dimensões da vida pessoal e coletiva. Assim, possibilitam-nos instrumentos teórico-práxicos para libertação integral, não só como sujeitos, mas enquanto sociedade, impelindo-nos a uma nova ordem social justa e igualitária. Consequentemente, o apelo à "responsabilidade do outro" e "pelo próximo", que este rosto (Outro) traz está concretamente, existencialmente e historicamente marcado. O "outro", de quem assinala Dussel, é o outro com um rosto, o outro concreto, em milhões de rostos que carregam as marcas do sangue, os sulcos da fome e da humilhação. Esta crítica, o autor não faz no nível das argumentações metafísicas, mas, sim, no plano humano das opressões historicamente estabelecidas. Em outras palavras, poderíamos falar numa ética da libertação como fundamentação ética e radical para a realização humana (DUSSEL, 1986). O “outro” negado de Dussel é, nesse contexto, o oprimido que assinala Freire, uma vez que o mesmo sempre buscou uma práxis dentro de seu país, sendo incontestável que o "oprimido" (que mencionava em seus escritos) significa o encobrimento de todos os povos da América Latina ${ }^{3}$ (DUSSEL, 1993).

A devida e necessária aproximação entre exclusão latino-americana e reconhecimento da solidariedade humana como ponto de partida para uma redefinição do atual projeto societário requer a incorporação de tais categorias no modo de abordagem da realidade, visando transformá-la radicalmente. Tal abordagem envolve compreensões da questão ambiental fruto de sistema colonizador, dominante e perverso que, por muitos séculos, alija o povo latino-americano de sua real condição e realização (ASSMANN; SUNG, 2000).

A contribuição de Paulo Freire põe em evidência os fundamentos filosófico-políticos na sua teoria do conhecimento e ação no mundo, que denominamos educação libertadora. Uma das principais concepções da educação libertadora é a de que a educação é uma atividade em que os sujeitos, educadores e educandos, mediatizados pelo mundo, educam-se em comunhão (TOZONI-REIS, 2006). A esse processo Freire (1993) chama "conscientização", isto é, inter -relação de sujeitos em diálogo que aprofundam o conhecimento da realidade vivida e de sua própria condição. Em vista disso, a educação libertadora é uma alternativa política à educação tradicional, a qual ele denominou "educação bancária", que, por opção política e metodológica de caráter "pacificador", realiza-se por simplesmente transmitir conhecimentos de educadores para educandos sem promover uma crítica radical. Por sua vez, a educação libertadora objetiva

\footnotetext{
${ }^{3} \mathrm{Na}$ crítica histórica de Zanotelli (2007, p. 14), há o seguinte questionamento: “Quais são estes traços identitários? Somos latino-americanos? Se o somos, não aceitamos facilmente que o sejamos segundo a visão preconceituosa que os países do Primeiro Mundo têm de nós. Mas o fato de sermos tratados preconceituosamente, estigmatizados como indolentes, preguiçosos, andarilhos, improvisadores, não muito sérios em cumprir os compromissos empenhados, etc... de não termos nem espaço, voz e vez nos meios de comunicação daqueles países, o fato ainda de sermos esquecidos e negados, mesmo e especialmente nos fatos em que somos lembrados (carnaval, futebol e escândalos) essa contraposição, essa discriminação, é também um lugar de nossa identificação. É preciso recolher com cuidado os vetores de nossa identidade e o processo de nossa identificação".
} 
questionar as relações dos homens entre si e deles com o mundo, criando condições para um processo de desvelamento do mundo que tem como prioridade transformá-lo socialmente. Entende-se que a educação não é a garantia das transformações sociais, mas que as transformações são impossíveis sem ela, sem uma visão crítica da realidade.

Paulo Freire (1993), num dos subtítulos do primeiro capítulo de sua Pedagogia do Oprimido, revela que: Ninguém liberta ninguém, ninguém se liberta sozinho: os homens se libertam em comunhão. A Pedagogia da Libertação e sua expressão Ética Universal do Ser Humano surgem de um processo histórico de libertação dos povos latino-americanos, expresso, também, em outras formulações teórico-metodológicas, como: a Filosofia da Libertação ou Ética da Libertação, a Teologia da Libertação, o Teatro do Oprimido de Augusto Boal e dos Movimentos de Educação e de Cultura Popular (ANDREOLA, 19--?). A Pedagogia do Oprimido de Freire tem seu projeto histórico-político pertencente à humanidade, dada a sua universalização. Dessa forma, a Pedagogia do Oprimido é um projeto coletivo que, se assumido com liberdade e criatividade, visa um projeto de emancipação. Este processo histórico de transformação e libertação é desenvolvido no diálogo e no fazer conjunto com os sujeitos históricos, a multidão dos oprimidos, que constituem a "comunidade das vítimas", segundo Dussel (2000), dos “oprimidos”, segundo Freire (1993).

Já em sua Pedagogia da Autonomia, Freire (1997) nos alerta para o discurso globalizante do qual "sua ética" não é a do ser humano, sua ética é do mercado. Por sua vez, a única condição capaz de alicerçarmos uma rebeldia contrária a este sistema, é a ética da solidariedade humana. Dessa maneira, Freire pensa ética e educação a partir de uma visão teorizada da prática, que, embora não reduzida à experiência empírica, seja capaz de tencionar axiomas filosóficos e pedagógicos que, historicamente marcados, constituem dimensões intrínsecas para a responsabilidade política do educador. Sua contribuição, portanto, foi fundamentar a educação epistemologicamente enquanto bases éticas e políticas, colocando em cena o sujeito não visto sob perspectiva metafísica, mas em sua própria condição histórica; numa relação dialética com outros sujeitos (GHIGGI, 2003). O que novamente nos impele na necessária ação política no mundo para transformá-lo, e, nessa direção, impõe-se a coerência ético-política no diálogo verdadeiro, portanto igualitário (ZITKOSKI, 2007).

Vislumbra-se, aí, um projeto pedagógico de libertação, uma práxis revolucionária em um projeto baseado na conscientização, que, em Paulo Freire, toma conotação eminentemente política, transformando-se numa relação que deve ser superada. No entender de Tozoni-Reis (2006, p. 104):

Para a pedagogia libertadora, a forma de trabalho educativo é o grupo de discussão, que conduz o processo educativo buscando os conteúdos problematizadores, realizando as discussões, compartilhando as descobertas, definindo as atividades e os temas geradores como ponto de partida para a decodificação das sílabas e, principalmente, a decodificação do mundo social, histórico, político e cultural onde vivem os oprimidos nas sociedades desiguais.

Por tudo isso, a libertação social e política estão dialeticamente relacionadas, sendo compreendidas no processo de vir-a-ser superado na contradição opressor-oprimido/colonizador-colonizado. Nesse âmbito, a pedagogia do oprimido colabora por ser uma pedagogia do 
ser humano nas mais diversas e complexas relações. Ou seja, o educador tem de agir na práxis, e para tal precisa ser educado/educar/educar-se, não lhe sendo suficiente o simples contato distanciado com aqueles aos quais se destina sua tarefa. E é nesse horizonte que o pensamento de Paulo Freire e Enrique Dussel possuem reconhecimento em suas premissas políticas, que se tornam essenciais para o debate ambiental.

Ao refletirmos uma interdisciplinaridade ambiental mais aberta aos problemas éticos, humanos e políticos, não seria errôneo afirmar que os confrontos epistemológicos devem se materializar, na medida em que, assumindo posições críticas, o pesquisador deverá disponibilizar, de modo coerente e refletido, as mais diversas informações ao mundo da sala de aula. Condição que deve ser orientada por meio de uma busca compartilhada nas pesquisas que possam trazer provocações e contribuições para as "demandas humanas". Em outras palavras, queremos apontar para a busca, do ponto de vista educativo, de uma originalidade entre dialética, interdisciplinaridade e ambiente que dê vazão aos engajamentos histórico-políticos da realidade latino-americana, bem como da construção de um pensamento vivo, crítico, humanístico e libertador na maneira de conceber a sociedade. Asseveramos que,

Educação Ambiental é dimensão da educação, é atividade intencional da prática social, que imprime ao desenvolvimento individual um caráter social em sua relação com a natureza e com os outros seres humanos, com o objetivo de potencializar essa atividade humana, tornando-a mais plena de prática social e de ética ambiental. Essa atividade exige sistematização através de metodologia que organize os processos de transmissão/apropriação crítica de conhecimentos, atitudes e valores políticos, sociais e históricos. Assim, se a educação é mediadora na atividade humana, articulando teoria e prática, a educação ambiental é mediadora da apropriação, pelos sujeitos, das qualidades e capacidades necessárias à ação transformadora responsável diante do ambiente em que vivem. Podemos dizer que a gênese do processo educativo ambiental é o movimento de fazer-se plenamente humano pela apropriação/ transmissão crítica e transformadora da totalidade histórica e concreta da vida dos homens no ambiente. (TOZONI-REIS, 2004, p. 147)

\section{Considerações finais}

A linha de argumentação central desenvolvida neste ensaio foi no sentido de afirmar que a Educação Ambiental crítica e a produção do conhecimento nesta, em uma perspectiva interdisciplinar, só poderá se manter enquanto materialidade que contribui para potencializar a transformação da práxis pedagógica se assumir a criticidade de suas proposições. Essa criticidade se relaciona à radicalidade da transformação social que respeite a alteridade; e ao método dialético, que tem, na contradição e na totalidade, conceitos fundantes para a compreensão do ser social e do movimento histórico do real.

No campo epistemológico crítico, há a necessidade de superarmos as formulações advindas da filosofia do sujeito como afirmam Jantsch e Bianchetti (2004). Para isso, é relevante 
contextualizar historicamente o advento da fragmentação ocorrida e imposta pela divisão do trabalho. Ao mesmo tempo, é preciso entender que a interdisciplinaridade ocorre na relação entre disciplinas científicas e escolares e saberes (SILVA, 2009). A práxis interdisciplinar não se resolve apenas no trabalho de equipe, em um movimento interior de descoberta ou em parceria, como assinala Fazenda $(1979,1991)$. A sociedade como um todo e o modelo de racionalidade nela constituído estão norteados pelos preceitos da fragmentação constituída historicamente. Portanto, a transformação metodológica tanto quanto a epistemológica se correlacionam com a dialética entre indivíduo e sociedade em suas potencialidades de mudança social. Para a ciência e a educação, a mudança social que engendraria a efetividade da interdisciplinaridade esbarra na organização do trabalho capitalista.

A materialidade do sistema necessita de análises para entendermos este contexto, a fim de refletirmos sobre o impacto que a interdisciplinaridade pode gerar numa organização escolar, com seus tempos, hierarquização de conteúdos, distribuição de aulas, avaliação do ensino e do trabalho do professor (SILVA, 2009).

Ao se buscar a interdisciplinaridade vinculada à educação ambiental crítica, é preciso ter visão crítica da própria ciência, enquanto instituição social e modos de conceber o real e produzir conhecimento e meios instrumentais de agir no mundo. Nesse processo de busca pela mudança paradigmática é necessária, portanto, a construção de mediações (SILVA, 2009). Portanto, ser interdisciplinar é reconhecer-se dentro de um processo em construção pautado pela problematização da disciplina e seus objetos específicos de pesquisa, e dessa com suas interconexões sociais, culturais e ambientais.

Afirmamos que a função de uma educação ambiental crítica e interdisciplinar é estar à altura dos desafios da sociedade chamada sociedade capitalista, justamente, delineando uma teoria que sirva de enfrentamento das atuais condições sociais, culturais e políticas, cuja tarefa é mais complexa do que o paradigma ambiental tradicional promete explicar, por vezes complexo apenas no entendimento da dinâmica natural, desconsiderando a dinâmica social-natural. Sabemos que a sociedade como um todo e o modelo de racionalidade nela instituída estão alicerçados por modelos de uma fragmentação constituída historicamente. A transformação metodológica tanto quanto a epistemológica se correlacionam com a dialética entre indivíduo e sociedade em suas potencialidades de transformar socialmente. Ou seja, para a educação ambiental crítica, a transformação social que produz a efetividade da interdisciplinaridade vai de encontro à organização capitalista. Tal forma de organização permeia a subjetividade instaurada pelas formas de conceber a interdisciplinaridade na educação ambiental, que entendemos ser um marco relevante na forma de compreender a materialidade presente nas relações ambientais a partir do conhecimento do todo, das articulações e das suas contradições. Assim, argumentamos que, no desenvolvimento interdisciplinar, é preciso considerar os componentes ontológicos e históricos de intervenção humana no ambiente, cabendo, aos processos de educação ambiental crítica, refletirem sobre a dinâmica da relação sociedade-natureza, os quais, sem esta dimensão, tornam o debate ambiental simplificado, fragmentado e despolitizado pela negação da materialidade e das contradições contidas nas relações sociais. 
Costa, C. A. S.; Loureiro, C. F. B.

\section{Referências}

ANDREOLA, B. Freire e Habermas: aproximações possíveis e convergências impossíveis. [S.l: s.n, 19--?].

ASSMANN, H. Reencantar a educação. Petrópolis: Vozes, 1999.

ASSMANN, H.; SUNG, J. M. Competência e sensibilidade solidária. Petrópolis: Vozes, 2000.

BIANCHETTI, L.; JANTSH, A. (Org.). Interdisciplinaridade: para além da filosofia do sujeito. In: Vozes, 2004. p. 11-24.

BRASIL. Lei n 9.795, de 27 de abril de 1999. Dispõe sobre a educação ambiental, institui a política nacional de educação ambiental e dá outras providências. Diário Oficial de União, Brasília, 28 abr. 1999. Disponível em: <http://www.planalto.gov.br/ccivil_03/Leis/L9795. htm>. Acesso em 18 maio 2015.

\section{Ministério da Educação. Diretrizes curriculares nacionais para a educação} ambiental. Brasília, 2012.

Parâmetros curriculares nacionais: meio ambiente e saúde. Brasília, 1997.

COSTA, C. A. S. Filosofia latino-americana: pressupostos para a "libertação ambiental". In: ENCONTRO DE PESQUISA EM EDUCAÇÃO AMBIENTAL, 6., 2011, Ribeirão Preto. Anais... Ribeirão Preto: USP, 2011.

DIAS, G. F. Educação ambiental: princípios e práticas. 8. ed. São Paulo: Gaia, 2003.

DUSSEL, E. 1492: o encobrimento do outro: a origem do mito da modernidade: conferências de Frankfurt. Petrópolis: Vozes, 1993.

Ética da libertação. Petrópolis: Vozes, 2000.

Método para uma filosofia da libertação. São Paulo: Loyola, 1986.

FAZENDA, I. C. A. Integração e interdisciplinaridade no ensino brasileiro: efetividade ou ideologia. São Paulo: Loyola, 1979.

Interdisciplinaridade: um projeto em parceria. São Paulo: Loyola, 1991.

FOLLARI, R. Interdisciplina e dialética: sobre um mal entendido. In: JANTSH, A.;

BIANCHETTI, L. (Org.). Interdisciplinaridade: para além da filosofia do sujeito.

Petrópolis: Vozes, 2004. p. 127-141.

FOSTER, J. B. A ecologia de Marx: materialismo e natureza. Rio de Janeiro: Civilização Brasileira, 2005.

FREIRE, P. Pedagogia do oprimido. 22. ed. Rio de Janeiro: Paz e Terra, 1993.

FREIRE, P. Pedagogia da autonomia. São Paulo: Paz e Terra, 1997. 
FRIGOTTO, G. A interdisciplinaridade como necessidade e como problema nas ciências sociais. In: JANTSH, A.; BIANCHETTI, L. (Org.). Interdisciplinaridade: para além da filosofia do sujeito. Petrópolis: Vozes, 2004. p. 25-50.

GHIGGI, G. Ética, autoridade e liberdade em Paulo Freire. In: ANDREOLA, B.; DALLA VECHIA, A. (Org.). Ética: diversidade e diálogo na produção de referências para a educação. Pelotas: Seiva, 2003. p. 13-37.

GORENDER, J. Apresentação. In: O CAPITAL. São Paulo: Nova Cultural, 1996. p. 5-66. (Os economistas).

JANTSCH, A. P.; BIANCHETTI, L. Imanência, história e interdisciplinaridade. In: (Org.). Interdisciplinaridade: para além da filosofia do sujeito. Petrópolis: Vozes, 2004. p. 177-194.

KOSIK, K. Dialética do concreto. Rio de Janeiro: Paz e Terra, 1978.

LOUREIRO, C. F. B. Complexidade e dialética: contribuições à práxis política e emancipatória em educação ambiental. Educação \& Sociedade, Campinas, v. 26, n. 93, p. 1473-1494, 2005. Disponível em: <http://dx.doi.org/10.1590/S0101$73302005000400020>$. Acesso em: 14 maio 2015.

. Crítica ao fetichismo da individualidade e aos dualismos na educação ambiental.

Educar em Revista, Curitiba, n. 27, p. 37-53, 2006a. Disponível em: < http://dx.doi. org/10.1590/S0104-40602006000100004>. Acesso em: 14 maio 2015.

. Educação ambiental e "teorias críticas". In: GUIMARÃES, M. (Org.). Caminhos da educação ambiental: da forma à ação. Campinas: Papirus, 2006b. p. 51-86.

. Educação ambiental transformadora. In: LAYRARGUES, P. P. (Coord.).

Identidades da educação ambiental brasileira. Brasília: Ministério do Meio Ambiente, 2004. p. 65-84. Disponível em: <http://www.mma.gov.br/estruturas/educamb/_arquivos/ livro_ieab.pdf $>$. Acesso em: 14 maio 2015.

2012.

Trajetória e fundamentos da educação ambiental. 4. ed. São Paulo: Cortez,

LOUREIRO, C. F. B. et al. Contribuições da teoria marxista para a educação ambiental crítica. Cadernos CEDES, Campinas, v. 29, n. 77, p. 81-97, Jan./Abr. 2009. Disponível em: <http://dx.doi.org/10.1590/S0101-32622009000100006>. Acesso em: 14 maio 2015.

LUKÁCS, G. Prolegômenos: para uma ontologia do ser social. São Paulo: Boitempo, 2010.

MARX, K. Manuscritos econômico-filosóficos e outros textos escolhidos. 4. ed. São Paulo: Nova Cultural, 1987.

Para a crítica da economia política: salário, preço e lucro: o rendimento e suas fontes; a economia vulgar. São Paulo: Abril Cultural, 1982. (Os economistas).

MARX, K.; ENGELS, F. A ideologia alemã. São Paulo: Grijalbo, 1977.

MÉSZÁROS, I. A teoria da alienação em Marx. São Paulo: Boitempo, 2006. 
Costa, C. A. S.; Loureiro, C. F. B.

MÉSZÁROS, I. O método I: a natureza da natureza. 2. ed. Porto Alegre: Sulina, 2003.

MORIN, E.Educar na era planetária: o pensamento complexo como método de aprendizagem no erro e na incerteza humana. São Paulo: Cortez; Brasília, DF: Unesco, 2003.

OLIVEIRA, A. R. Educação e exclusão: uma leitura ancorada em Karl Marx. 2002. 230 f. Tese (Doutorado em Educação) - Universidade Federal do Rio Grande do Sul, Porto Alegre, 2002.

PRADO, E. F. S. Uma nova fase do capitalismo ou um novo modo de produção capitalista?

Revista Outubro, São Paulo, n. 13, p. 47-57, 2005. Disponível em: < http:/ /www. revistaoutubro.com.br/edicoes/13/out13_03.pdf>. Acesso em: 14 maio 2015.

PRIGOGINE, I.; STENGERS, I. A nova aliança. 3. ed. Brasília: Editora da UnB, 1997.

QUINTAS, J. S. Educação no processo de gestão ambiental pública: a construção do ato pedagógico. In: LOUREIRO, C. F. B.; LAYRARGUES, P. (Org.). Repensar a educação ambiental: um olhar crítico. São Paulo: Cortez, 2009. p. 33-77.

SCHMIED-KOWARZIK, W. Pedagogia dialética. São Paulo: Brasiliense, 1983.

SEVERINO, A. O uno e o múltiplo: o sentido antropológico do interdisciplinar. In: JANTSH, A.; BIANCHETTI, L. (Org.). Interdisciplinaridade: para além da filosofia do sujeito. Petrópolis: Vozes, 2004. p. 159-175.

SILVA, L. F. Reflexões sobre interdisciplinaridade e educação ambiental crítica. Pesquisa em Debate, São Paulo, v. 6, n. 2, p. 1-15, 2009. Disponível em: <http://www.pesquisaemdebate. net/docs/pesquisaEmDebate_11/artigo_1.pdf>. Acesso em: 14 maio 2015.

TOZONI-REIS, M. Educação ambiental: natureza, razão e história. Campinas: Autores Associados, 2004.

. Temas ambientais como "temas geradores": contribuições para uma metodologia ambiental, crítica, transformadora e emancipatória. Educar, Curitiba, n. 27, p. 93-110, 2006. VÁSQUEZ, A. S. Filosofia da práxis. São Paulo: Expressão Popular, 2008.

ZANOTELLI, J. América Latina: raízes sócio-político-culturais. 3. ed. Pelotas: Educat, 2007.

ZITKOSKI, J. A pedagogia freireana e suas bases filosóficas. In: GHIGGI, G.; SILVEIRA, F.; PITANO, S. (Org.). Leituras de Paulo Freire. Pelotas: Seiva, 2007. p. 229-248.

Artigo recebido em 25/12/13. Aceito em 27/03/15. 